Meta

Journal des traducteurs

Translators' Journal

\title{
The Process of Comprehension from a Psycholinguistic Approach - Implications for Translation
}

\section{Anna Hatzidaki}

Volume 52, numéro 1, mars 2007

Traductologie : une science cognitive

URI : https://id.erudit.org/iderudit/014715ar

DOI : https://doi.org/10.7202/014715ar

Aller au sommaire du numéro

Éditeur(s)

Les Presses de l'Université de Montréal

ISSN

0026-0452 (imprimé)

1492-1421 (numérique)

Découvrir la revue

Citer cet article

Hatzidaki, A. (2007). The Process of Comprehension from a Psycholinguistic Approach - Implications for Translation. Meta, 52(1), 13-21.

https://doi.org/10.7202/014715ar
Résumé de l'article

Cet article présente l'approche psycholinguistique du processus de compréhension du langage c'est-à-dire la façon dont on représente et utilise le sens littéral et le sens figuré des mots et des phrases, la façon dont on décode l'intention communicative des éléments linguistiques, ainsi que la participation de la mémoire dans ce décodage. L’analyse des recherches psycholinguistiques sur les processus mentaux à la base de la compréhension du langage met en avant le lien étroit entre la traductologie et la psycholinguistique. En effet, les connaissances acquises grâce à la psycholinguistique permettent de développer les théories ainsi que les pratiques utilisées pour la formation des futurs traducteurs. 


\title{
The Process of Comprehension from a Psycholinguistic Approach - Implications for Translation
}

\author{
ANNA HATZIDAKI \\ University of Edinburgh, Edinburgh, United Kingdom \\ annh_22@yahoo.com
}

\section{RÉSUMÉ}

Cet article présente l'approche psycholinguistique du processus de compréhension du langage c'est-à-dire la façon dont on représente et utilise le sens littéral et le sens figuré des mots et des phrases, la façon dont on décode l'intention communicative des éléments linguistiques, ainsi que la participation de la mémoire dans ce décodage. L'analyse des recherches psycholinguistiques sur les processus mentaux à la base de la compréhension du langage met en avant le lien étroit entre la traductologie et la psycholinguistique. En effet, les connaissances acquises grâce à la psycholinguistique permettent de développer les théories ainsi que les pratiques utilisées pour la formation des futurs traducteurs.

\section{ABSTRACT}

The present paper provides a psycholinguistic approach to the process of comprehension. Namely, how people represent and make use of the literal and figurative meaning of words and sentences, how they decode the communicative purpose of linguistic elements, and how memory is involved in this decoding. By explaining the findings of psycholinguistic studies on the mental processes that underlie the comprehension of language, we show (i) how closely related translatology and psycholinguistics can be, and (ii) suggest ways in which knowledge of the latter may be used to both enrich theories and practices of the former, and in the instruction of future translators.

\section{MOTS-CLÉS/ KEYWORDS}

comprehension processes, literal and figurative meaning, psycholinguistics, translatology

\section{Introduction}

The main object of research in psycholinguistics is the study of the cognitive processes that underlie the comprehension and production of language, and the way the cultural environment interacts with these two (e.g., Harley 2005). Among the most frequent experimental methods researchers use in this field to explore these issues it is possible to find the following; reaction time measures, that is, the time it takes a person to respond to a stimulus or perform a certain task within which certain linguistic variables (e.g., semantic and morphophonological properties of language constituents) and extra-linguistic variables (e.g., age of acquisition and learning environment) have been manipulated; priming, whereby the influence of exposure to previous semantic and/or morphosyntactic information on current language behavior is tested between a prime and a target; and stroop-like paradigms, within which the properties between two stimuli are manipulated in such a way as to show whether their relationship facilitates (facilitation effects) or inhibits (interference effects) processing. Physiological and neurodiagnostic techniques commonly used include; eye-tracking; 
ERPs (Event Related Potentials), measuring electrical activity in the brain after a particular event; and fMRIs (functional Magnetic Resonance Imaging), measuring blood flow change and oxygen use in the brain as a response to a stimulus. (For the purposes of this paper, we will not address in detail those experimental methods that have been used to test certain assumptions. However, we emphasize that all the theories and models presented here are supported by experimental evidence).

Given that the focus of research in translatology is the observation and analysis of language processing in translation, it becomes evident that psycholinguistics and translatology are interconnected. Moreover, since translatology has mainly dealt with the competence and performance of bilingual or multilingual speakers during translating, whereas psycholinguistics has dealt with the cognitive aspects of language-use, we propose that translatology may profit in adopting an interdisciplinary approach to the study of translation, thus enriching its current theories and practices while using a wide variety of well-controlled experimental methods.

In this paper, we first briefly clarify notions relating to meaning, and then discuss the major findings of psycholinguistic literature on the mental processes of comprehension at the three levels of language representation (i.e., how meaning is represented and decoded at lexical, sentential, and textual level). In particular, we introduce established psycholinguistic theories of how people represent the meaning of words and word-pairs (compound nouns), and describe the most influential models that have been proposed to account for sentence as well as text comprehension during literal and figurative meaning processing. We also present linguistic, extra-linguistic, and psycholinguistic factors that may affect comprehension by making it either easier or more difficult. Finally, we conclude by discussing the implications of the findings from psycholinguistic research for translatology.

\section{Basic Concepts of Meaning}

Language comprehension appears to be a very simple and natural process for speakers, listeners or readers. However, a great deal of research has been carried out to identify the stages our thought goes through before we are able to construct an interpretation of an intended message (e.g., Lakoff 1971; Jackendoff 1997; Fodor 2000).

For an utterance to be meaningful, certain requirements have to be met. For instance, people make use of words in different ways depending on communicative situations and their intentions. Consequently, the recipients of oral or written speech must be able to differentiate between the nuances these words convey and the discourse environment within which they are used, to be able to comprehend the meaning and intent of any speech act (e.g., Searle 1969).

Prior to presenting the main issues that are relevant to the comprehension of meaning, it is worth distinguishing between two concepts that are closely related to meaning; that is, between a word's denotation and a word's connotation. The former refers to the actual meaning of a word (what is usually provided as a first definition for a word in a dictionary). The latter refers to associations people make based on cultural-specific or other personal factors (ideological, emotional, and so on) (e.g., Fodor, Bever and Garrett 1974). For example, the denotative meaning of the adjective Mediterranean is "someone who comes from a region between South Europe and North Africa” (Collins Compact English Dictionary 1993). However, its connotative 
meaning may relate to people who are more demonstrative than others, warm and friendly. In this paper, I will mainly be concerned with the concept of denotation.

\section{Representation of the Meaning of Words}

Certain theories have been proposed to account for how words are represented in our mind. One of them is the Reference Theory of Meaning which equates a word's meaning with what that word refers to in the world (Putnam 1975). For example, the noun drawer is identified with a sliding box-shaped part of a piece of furniture used for storage. On the other hand, the Prototype Theory of Meaning assumes that a word's meaning can be derived from a bundle of features, no one of which is individually either necessary or sufficient (Rosch 1973b). According to this view, a prototype constitutes the way knowledge is organized, and can help people categorize concepts by checking whether these concepts share some features with each other or not. For example, a pigeon may be considered a prototypical bird because it possesses most features other members of its category (family) possess - it flies, has feathers, wings, short legs, and so on.

However, a number of counterarguments have been expressed against each one of these accounts, which cast doubt on the validity of their premises. With respect to the reference account, it has been argued that many words do not have a concrete reference, yet, they are meaningful, or that two utterances may refer to the same thing but have different meanings. As far as the prototype approach is concerned, the loose category boundaries, posed by the imprecise nature of the features this theory assumes, do not make clear how people are able to understand words that may lack features that would otherwise be considered central to meaning specification.

The view most researchers agree with regarding the way meaning is represented in the mind is that of the Decompositional Theory of Meaning, which holds that the meaning of an utterance can be derived if the latter is broken down into its component semantic features (Katz 1972). For example, the word trousers can be decomposed into the following list of features; + object, + inanimate, - more than one entity, and so on. In particular, it is assumed that the combination of semantic features creates conceptual dependencies which, with the help of inferences, lead to comprehension. People draw inferences when they go beyond explicitly presented or verbally stated information by making use of various domains of knowledge such as encyclopaedic, contextual, and situational information (Bierwisch and Schreuder 1992). We will return to the use of inferences later, in the section relating to figurative meaning processing.

\section{Comprehension of Word Combinations}

We mentioned above that people derive the meaning of a word through decomposition into semantic features and by drawing inferences from the word's feature representation. The next question we shall deal with is how comprehension is achieved when two words are put together, and how we are able to understand word combinations, particularly noun phrases which we have never encountered before (for example, the phrase cumquat bowl).

It has been suggested in the psycholinguistic literature (e.g., Wisniewski 1997; Shoben and Gagne 1997) that people's interpretations of word combinations may rely 
on a number of linguistic and extra-linguistic factors such as; (i) thematic relation, that is, what kind of association may exist between two entities; thus, for a word combination as in the example given above, the relation between the two lexical items would be "a bowl that is full of cumquat"; (ii) property link, referring to the properties of the two entities and how these can combine to lead to a meaningful utterance, e.g., "a bowl of orange colour like a cumquat"; (iii) hybridization, whereby the meaning of the word combination is equally shaped by both constituents; for example, a footballer doctor is a person who is both a doctor and a footballer; and (iv) past experience, referring to the knowledge people have acquired from previous use of one of the two constituents, with respect to the meaning that each constituent may carry when combined with others; for example, the noun river, when it is used in word combinations, usually denotes a location relation (e.g., river bank, river bed), hence a similar interpretation would be attributed to another combination that would include the word river (e.g., river mouth).

Interestingly, it is assumed that people show a preferable reliance to stereotypical knowledge in order to understand the meaning of word combinations. That is, they tend to resort to the thematic relation first, and only when this does not lead to a meaningful interpretation do they bring into play any of the other factors mentioned above (e.g., Harley 2005). As we shall see shortly, this pattern of language disambiguation also emerges in sentence comprehension both during literal and figurative meaning processing.

\section{Sentence Comprehension during Literal Meaning Processing}

Now that we have addressed the psycholinguistic perspective on how people represent word meanings and decode lexical information, let us move on to a larger unit of language representation.

In order to be able to understand the structure of sentences, people have to combine different sources of information relating to language constituents. That is, they have to be able to retrieve; (i) the semantic representation of each lexical item in a sentence, (ii) the grammatical information these items carry about their nature, (iii) the syntactic information about other items they can combine with (Chomsky 1980; 1986), and (iv) the kind of dependencies they may form (Pickering and Branigan 1998). Thus, thematic roles that specify the relationship between the constituents (e.g., agent, theme, recipient, instrument, and so on) and grammatical relations (e.g., subject, object, etc.) have to be assigned. Finally, people tend to tie the representation that is built through all these processes to the discourse context. In other words, the precise meaning that is assigned to a sentence is highly correlated with the discourse environment within which this sentence is presented.

However, natural occurring speech is not always straightforward, a fact that may posit an additional burden to the already complex process of syntactic structure computation (parsing). Sentence ambiguity is a frequently studied example of such occurrences. How do people manage to access the intended meaning of a sentence that admits two different interpretations? In a sentence such as The girl watched the boy with the binoculars, one possible interpretation is that a girl watched a boy who carried binoculars, and if there were other boys in the scene, the emphasis would be placed on the boy with the binoculars, not anyone else. An alternative interpretation 
is that a girl watched a boy with the help of binoculars. So what kind of cues do we use to avoid ambiguity?

The most dominant models that have been proposed to account for understanding ambiguous sentences are the Garden Path and the Constraint-based models. According to the Garden Path Model (Frazier and Fodor 1978), language processing operates incrementally in two stages. Initially, readers or listeners construct a single representation of the sentence based on syntactic information by employing certain linguistic principles. The minimal attachment principle favours the simplest syntactic structure, while the late closure principle involves people's tendency to attach each lexical item to the clause/phrase being currently processed. Thematic role information is only invoked in the second stage. In case the interpretation that is produced based on the above processes does not fit in with further contextual information or people's expectations, a new parsing follows.

In contrast, the constraint-based view assumes that semantic, syntactic, discourse and other extra-linguistic information affects sentence structure computation in one go (e.g., Tanenhaus, Carlson and Trueswell 1989). The construction that is mostly activated, that is, the interpretation that receives support from the majority of information sources, is the one that we finally select. Although there are a number of studies which provide evidence for this account, support for the Garden Path theory comes from a wider range of research with normal and brain-damaged participants, showing that syntactic processing precedes semantic processing and is independent of it (e.g., Ainsworth-Darnell, Shulman and Boland 1998).

\section{Sentence Comprehension during Figurative Meaning Processing}

So far we have presented psycholinguistic views on how listeners and readers process literal meaning, that is, how the essential meaning of expressions is understood. Next, we discuss what is assumed about language processing when the meaning of an utterance goes beyond that of common use.

Harley (2005) proposed three main types of figurative speech; metaphors, idioms, and indirect requests. Metaphorical expressions comprise; simile whereby one thing is likened to another of a different category (e.g., Ewan drank like a fish); strict metaphor, namely, a single-use metaphor (e.g., Ewan burst into tears); and synecdoche, whereby a part is substituted for a whole or a whole for a part (e.g., Fifty head of cattle, for Fifty cows). To understand the structure of these sentences the Three-stage Model (Clark and Lucy 1975) postulates that people first derive the literal meaning (in the way we described in the preceding section), which they then test against the context to check for its plausibility. In case it appears to be implausible, further interpretations are attempted.

For idioms, that is, a combination of words which, when considered as a whole, have a different meaning from the meaning suggested by the individual words (e.g., Make shellfish while the sea is out; Scottish idiom), it is assumed that they are represented and stored in memory as a single lexical entry, unrelated to the lexical entries of each one of the components that build a phrase such as the one above (Clark and Clark 1977; Gibbs 1980).

With respect to understanding indirect requests such as Can you pass the pepper, whereby the speaker does not ask her interlocutor whether she is physically able to 
perform this particular task but whether she is available or willing to do so, people appear to rely heavily on inferences (Shank 1976). As mentioned earlier, we draw inferences to construct a coherent meaning of oral or written speech, either by being guided by the actual meaning of words (logical inferences), or by making associations with the contextual environment (bridging inferences), and by employing background knowledge which may be relevant to the current state (elaborative inferences). Above all, as with any other kind of expression, recipients tend to seek the literal meaning first, and only when it does not make sense do they seek alternative meanings (Searle 1979). The same processing seems to apply to other acts of speech (e.g., irony and humour), which usually mean something else from what is actually stated.

\section{Text Comprehension}

Having presented the cognitive processes that underlie comprehension at the lexical and sentential level, next we describe what is assumed about the way sentences are combined to construct text representation and help in the decoding of a text's communicative purpose.

As with sentence comprehension, text comprehension also involves inferential activity. That is, during the process we present below, both information from the text itself and from readers' own world knowledge and expectations is used to build up meaningful representations. The text-comprehension theory that has received the most attention is the Processing Cycles Theory or Construction-Integration Theory (Kintsch 1988 ; 1994). According to this view, text representation is constructed by integrating each sentence representation into the context that has been formulated by preceding sentences. In this sense, every time a sentence is introduced, the whole text representation is updated. That is, during every sentence occurrence, ideas have to be reorganized and new relationships have to be established to include new information.

It is important to note that for this reorganization to take place the role of shortterm and long-term memory appears to be crucial (Tulving 1972). Short-term memory acts as a temporary storage space within which incoming material is processed. During this processing, additional information is provided by long-term memory (as this is where any kind of permanent linguistic and extra-linguistic information is stored). When a representation is constructed, linguistic material that has already been processed is deleted from short-term memory to allow new input to be processed.

\section{Factors that Affect Comprehension}

In this section, we list some of the factors that may facilitate or inhibit comprehension. These can be distinguished in factors relating to individual differences and in factors relating to the properties of the to-be-understood material.

With respect to individual differences, as with any other cognitive ability, comprehension skills may vary from one person to another, due to people's varying degrees of competence and performance (Chomsky 1968). In other words, what makes "good" and "less-good" comprehenders is the fact that some may acquire all the necessary linguistic and extra-linguistic information for understanding, but be unable to apply it because of physiological limitations (e.g., restricted short-term memory capacity due to age or brain damage), or inadequacy of operating under stressful conditions 
that may disrupt the process of comprehension (e.g., time pressure or noisy environment). On the other hand, others may be capable of dealing with external factors but not possess the required knowledge (e.g., background knowledge and languagespecific information) to successfully construct meaning representations.

Regarding the factors that are relevant to the to-be-understood material, it is expected that complex structures will be more difficult to understand than simple structures. The former create more relationships among linguistic elements, thus overloading the mind's processing capacity, whereas the latter do not need any extra cognitive abilities to be processed. The nature of a text, for example stylistics, clarity of expressed ideas, and so on, may also determine how successful the process of comprehension can be. Finally, factors such as familiarity and frequency have been found to facilitate comprehension since the more familiar we are with certain structures and the more frequently we use them the easier it is to understand them when we read or hear them.

\section{Conclusion}

The aim of this paper was to provide a brief introduction to the process of comprehension from a psycholinguistic perspective. We explained that comprehension of literal meaning for words and word combinations is based on the integration of semantic features and inferences. For sentences, meaning representations result from the assignment of thematic roles and determination of syntactic categories in combination with semantic information and background knowledge. Text comprehension employs much of the same processes as sentence comprehension, yet entails a more enhanced participation of short-term and long-term memory since the processing task is cognitively more demanding. With respect to comprehension of figurative meaning, we showed that people tend to derive the literal meaning of an utterance first, and only when its testing against context does not result in a plausible interpretation do they seek alternative interpretations. Regarding factors that may affect comprehension, we distinguished between comprehender-specific and material-specific factors.

Taking into account the information on language comprehension provided from a psycholinguistic approach, the following questions can be raised: In what ways can a psycholinguistic perspective contribute to the field of translation? How can knowledge from a different field be used in instructing future translators? We argue that an interdisciplinary approach to translation is imperative since the contribution of psycholinguistics can offer insight into cognitive processes translation is not able to tap into on its own. In this way, translation theories can be enriched by including variables that have not been considered until now. Moreover, the use of a wide range of experimental paradigms can provide scientific evidence to explain the process of comprehension during translation and justify the occurrence of translation problems and translation product variability (see also Wills 1982 and Lörscher 1991, for a similar view). Also, by experimentally manipulating certain variables, it will be possible to understand how the meaning of a text cannot be resolved based entirely on linguistic and often-cited extra-linguistic factors. Psycholinguistic factors such as frequency, preference, memory load, and so on have been found to play a crucial role as well. Last but not least, this knowledge can be used, not only, to improve machine translation applications, but also as a teaching tool to heighten future translators' awareness of comprehension pitfalls so that they can translate accurately and avoid nurturing misinterpretations. 


\section{REFERENCES}

Ainsworth-Darnell, K., Shulman, H. G. and J. E. Boland (1998): "Dissociating Brain Responses to Syntactic and Semantic Anomalies: Evidence from Event-Related Potentials," Journal of Memory and Language 38, pp. 112-130.

Bierwisch, M. and R. Schreuder (1992): “From Concepts to Lexical Items," Cognition 42, pp. 23 60.

Сномsкy, N. (1968): Language and Mind, New York, Harcourt Brace Jovanovich.

Сномsкy, N. (1980): Rules and Representations, New York, Columbia University Press.

Сномsкy, N. (1986): Barriers, CA, MIT Press.

Clark, H. H. and E. V. Clark (1977): Psychology and Language, New York, Harcourt Brace Jovanovich.

Clark , H. H. and P. LuCy (1975): “Inferring What was Meant from What was Said," Journal of Verbal Learning and Verbal Behavior 14, pp. 56-72.

Collins Compact English Dictionary (1993): London, Harper Collins Publishers.

Fodor, J. (2000): The Mind Doesn't Work That Way, CM, MIT Press.

Fodor, J., Bever, T. G. and M. F. Garrett (1974): The Psychology of Language: An Introduction to Psycholinguistics and Generative Grammar, New York, McGraw-Hill.

Frazier, L. and J. D. Fodor (1978): “The Sausage Machine: A New Two-Stage Parsing Model," Cognition 6, pp. 291-325.

GibBs, R.W. (1980): "Spilling the Beans on Understanding and Memory for Idioms in Conversation," Memory and Cognition 8, pp. 149-156.

Harley, T. (2005): The Psychology of Language. From Data to Theory, New York, Psychology Press.

JaCKendoff, R. (1997): The Architecture of the Language Faculty, CM, MIT Press.

KatZ, J. J. (1972): Semantic Theory, New York, Harper and Row.

Kintsch, W. (1988): “The Use of Knowledge in Discourse Processing: A Construction-Integration Model," Psychological Review 95, pp. 163-182.

Kintsch, W. (1994): “The Psychology of Discourse Processing," in Gernsbacher, M. A. (ed.), Handbook of Psycholinguistics, San Diego, Academic Press, pp. 721-740.

Lakoff, G. (1971): “On Generative Semantics," in Steinberg, D. D. and L. A. Jakobovits (eds.), Semantics: An Interdisciplinary Reader in Philosophy, Linguistics and Psychology, Cambridge, Cambridge University Press, pp. 232-296.

Lörscher, W. (1991): Translation Performance, Translation Process and Translation Strategies: A Psychological Investigation, Tubingen, Gunter Narr Verlag.

Pickering, M. J. and H. P. Branigan (1998): "The representation of verbs: Evidence from syntactic priming in language production," Journal of Memory and Language 39, pp. 633-651.

Putnam, H. (1975): “The Meaning of Meaning," in Gunderson, K. (ed.), Language, Mind, and Knowledge, Minneapolis, University of Minnesota Press, pp. 131-193.

Rosch, E. H. (1973b): “On the Internal Structure of Perceptual and Semantic Categories," in Moore, T. E. (ed.), Cognitive Development and the Acquisition of Language, New York, Academic Press, pp. 111-144.

Schank, R. C. (1976): Conceptual Information Processing, Amsterdam, North-Holland.

Searle, J. R. (1969): Speech Acts: An Essay in the Philosophy of Language, New York, Cambridge University Press.

Searle, J. R. (1979): "Metaphor," in Ortony, A. (ed.), Metaphor and Thought, Cambridge, Cambridge University Press, pp. 92-123.

Shoben, E. J. and C. L. Gagne (1997): "Thematic Relations and the Creation of Combined Concepts," in Ward, T. B., Sмith, S. M. and J. VAID (eds.), Creative Thought: An Investigation of Creative Structures and Processes, Washington, DC, American Psychological Association, pp. 31-50.

Tanenhaus, M. K., Carlson, G. N. and J. C. Trueswell (1989): “The Role of Thematic Structure in Interpretation and Parsing," Language and Cognitive Processes 4, pp. 211-234. 
Tulving, E. (1972): "Episodic and Semantic Memory," in Tulving, E. and W. Donaldson (eds.), Organization of Memory. New York, Academic Press, pp. 381-403.

WiLss, W. (1982): The Science of Translation. Problems and Methods, Tübingen, Narr.

Wisniewski, E. J. (1997): “When Concepts Combine," Psychonomic Bulletin and Review 4, pp. 167183. 